\title{
Research University as a source of competitive petrochemical engineers
}

Prof. Farida Tagirovna Shageeva, Kazan National Research Technological University Alfiya Ivanovna Lakhova

Inna Mikhailovna Gorodetskaya, Kazan National Research Technological University 


\section{Research University as a source of competitive petrochemical engineers}

Oil and gas chemical complex is a crucial sector of the economy with a multi-level technical equipment and adaptability with an innovative development vector. Large-scale innovation of the industry is largely determined by ensuring its production of highly skilled staff, training quality of that should be responded with fast-changing demands of the developing manufactures.

In modern conditions, the main goal of the petrochemical industry enterprises is to improve the quality of products, ensuring theirs competitiveness and as a result, the achievement of profit, which is the source of funds for the further development of enterprises [1].

During the transition from one stage of company development to another, there is an accumulation of organizational problems. These problems may be the result of making wrong management decisions that can be corrected through minor adjustments to the control system, or may be indicative of the approach of the next stage of the production life cycle, and, therefore, are related to the need for organizational change. Thus, an effective and stable activity of the company is largely dependent on how the administrative staff understands, evaluate and take into account organization life cycle and each stage of development.

Review of the status and prospects of the petrochemical complex, training experience and analysis of compliance of implemented staff training to industry requirements point to the increasingly manifested today contradiction between the objective need of innovative developing petrochemical complex in highly skilled staff and established system of training, not focused on current scientific and technological requirements of the industry [2].

Lack of staff holding competencies in the field of technology of production, processing, transportation, which will be able to rapid response to market conditions and rapidly changing economical situation, assess the conditions and consequences of their organizational and management solutions, project management in the field of high technologies, marketing researches, develop business plans of production and realization of products is one of the most urgent problems of modern high-tech industries in innovatively developing enterprises of petrochemical complex.

An effective way to solve this problem is implementation of Masters' multidisciplinary training, which will form competent, prognostic and innovation-oriented personnel able to ensure efficient operation of production at present and in terms of their future development, including technological project managers in high technology, capable of operating in the global capital markets [3]. This involves the development of the educational program "Life cycle managing of petrochemical enterprise", which will generate Masters' competencies in the field of chemical engineering, management and organization of petrochemical enterprises. The curriculum is designed in order to meet the requirements of Federal state educational standards of higher education of third generation towards the preparation for training direction "Chemical Technology". The total number of training sessions is 120.0 credit units, which corresponds to 4320 hours. The plan provides for 21 control point, including 2 coursework, 7 exams and 12 tests. 
Basic disciplines, such as the "Raw material base of petrochemical industry", "The technological structure and business activities of the enterprises," "Technical regulation in the oil and gas industry" and "Life-cycle management of petrochemical enterprise", ensuring the formation of common cultural and professional skills of future engineers, managers. Optional disciplines of the curriculum form the special competence. Forming of competencies set for the organization and management of petrochemical company is provided by a range of economic and management disciplines: "Innovation management in the petrochemical complex", "Business planning of petrochemical enterprises", "International Business", "Management of the finance company", etc.

Consolidation and deepening of theoretical knowledge on specific subjects of the curriculum of the educational program "Life cycle managing of petrochemical enterprise" ensures the master's passage of various types of practices: the industrial, research and scientific [4].

In the result of the implementation of the program "Lifecycle Management for petrochemical enterprise" was protected by three master's thesis. In the process of preparation of final qualifying works of students were able to acquire different skills. The work was carried out at the enterprises of petrochemical profile. They learned how to develop a logical system of managerial, organizational and technical measures ensuring the functioning of the production processes of the processing facility in accordance with the standards PISTEP and PIEBASE. They had the opportunity to analyze the market of raw materials refining and petrochemical industry for the selection of optimal source of raw materials and to predict the development of the commodity market.

The objectives of research and production practice is practical study of the content of the existing management activities, the best practices organization, security of life and the environment, solving scientific and practical problems, implementation of new scientific and engineering solutions to the existing and newly designed production facilities, design and lifecycle management of industrial enterprises and business units.

The aim of the practical training is a practical study of modern technological processes and equipment, mechanization and automation of production, organization of best practices, security of life and environmental protection. Masters acquaint with the production and technology.

The main purpose of the research practice (research) of a student is developing the ability of an independent scientific research, related to the decision of the complex professional tasks in terms of innovation.

However in recent years requires specialists with a narrowly profile. In 2015 it is planned protection in the educational program "Complex system of petrochemical engineering".

According to experts, global heavy oil reserves amount to more than 810 billion tons of Geological reserves of heavy oil in Russia reach 6-7 billion tons (40-50 billion barrels), but their application and extraction requires the use of expensive technologies. The educational program prepares specialists in the field of extraction and processing of heavy oil and gas hydrates. 
Production of high quality bitumen for road construction is a promising direction. Today the need of the industry in the bitumen, which is obtained from fractions of conventional and heavy oil, is more than 2.5 million tonnes. In addition, the prospect of development of natural bitumen is becoming more relevant due to the possibility of generating energy, alternative heating oil and natural gas. Given that the average annual rate of growth of demand for bitumen in the short term are expected to be within $10 \%$, by 2015 the volume of its use can reach 9-10 million tonnes.

This educational program will allow for large enterprises specialists of narrow profile. Each discipline allows you to acquire certain skills. For example, "Chemical technology of processing of oil residues and natural bitumen" introduces various types of destructive processes and schemes deepening of oil refining, and also teaches the ways and methods of processing which is difficult to dispose of products (light gases, asphalts, pitches).

Tatarstan has Russia's largest resources of natural bitumen. The main task of the Republic in the current difficult situation - attraction of investments and introduction of new effective methods of increasing the extraction of bitumen. A zero rate of mineral extraction tax, introduced in 2006 on the extraction of heavy oil and bitumen, will serve to further increase production efficiency.

In connection with the development of the educational program "Complex systems petrochemical engineering" in the direction of 240100 - "Chemical technology", which will provide enterprises with experts in the field of mining and processing of heavy and extra heavy crude oils is the priority direction of development for the entire oil industry of Russia and Tatarstan. The first issue will consist of 3 people.

It has established the following forms of cooperation with a number of large industrial enterprises of Russia ("TANECO", "Lukoil", "KIRISHI") for the organization of such practices in the Kazan National Research Technological University at the Department of Chemical Technology of oil and gas refining:

- Moonlighting of production workers as teachers (Department of Chemical Technology of oil and gas refining set up a branch in the department of OAO "LUKOILNizhegorodniinefteproekt" so that masters can acquire knowledge in a production environment in real terms);

- Scientific cooperation (employees of industrial enterprises are invited to the conference, the scientific school, the Olympics as lectures and members of the jury).

It is also important that students have the opportunity to go through all kinds of practices directly on the site of these enterprises.

References

1. The Energy Strategy of Russia for the period up to 2020. Online resource: http://www.domenergy.ru/files/Files/strategy.pdf

2. Gorodetskaya I.M. Socio-psychological aspects of lifelong education and professional retraining. // 2012. 15th International Conference on Interactive Collaborative learning, ICL 2012. Conference Paper. Source: Scopus

3. M.V. Zhuravleva Advanced staff training of specialists for petrochemical complex / M.V. Zhuravleva, P.N. Osipov, I.Sh. Abdullin // Education and self-development. - 2010. - № 3 - pp. 62- 67 
4. Shageeva F.T., Ivanov V.G. Contemporary technologies for training future chemical engineers / Interactive Collaborative Learning. IGIP International Conference, IGIP 2013, ICL2013, September 25-27, 2013, Kazan, Conference Paper. Source: Scopus

5. The Chemical Journal, december 2008. Online resource: http://vseonefti.ru/neft/tyazhelyenefti-Rossii.html 